\title{
Peningkatan Keterampilan Bagi Tim Analis Sistem PT. TAS Melalui Analisa dan Perancangan Menggunakan Enterprise Architect
}

\author{
Herny Februaryanti' ${ }^{1}$ Arief Jananto ${ }^{2}$, Wiwien Hadikurniawati ${ }^{3}$, Edy Winarno ${ }^{4}$ \\ 1,2,3,4Universitas Stikubank Semarang \\ e-mail: ${ }^{1}$ hernyfeb@edu.unisbank.ac.id, 2ajananto09@edu.unisbank.ac.id, \\ ${ }^{3}$ wiwien@edu.unisbank.ac.id, ${ }^{4}$ edywin@edu.unisbank.ac.id
}

\begin{abstract}
Abstrak
Tujuan kegiatan Pengabdian Kepada Masayarakat ini adalah memberikan pengetahuan dan keterampilan mengenai proses perancangan sistem dalam kegiatan pengembangan sistem bagi Tim Analis Sistem di PT. TAS Semarang. Analisa dan perancangan merupakan tahap didalam pengembagan sistem dengan tujuan untuk mendapatkan gambaran secara jelas serta detail apa saja yang akan dikerjakan. Kegiatan yang dilakukan adalah analisis kebutuhan fungsional dan nonfungsional sistem. Kebutuhan fungsional bertujuan untuk didapatkan informasi yang berisi proses-proses apa saja yang nanti akan dilakukan. Sedangkan kebutuhan nonfungsional dimaksudkan untuk mendapatkan informasi terkait dengan kebutuhan-kebutuhan meliputi properti perilaku-perilaku yang dimiliki oleh sistem. Tahap analisis tersebut menjadi kunci kesesuaian sistem yang akan dikembangkan dengan kebutuhan pengguna. Untuk itu penting sekali sebuah tim pengembang sistem untuk dapat melakukan analisis dengan benar serta menggunakan kaidahkaidah yang benar. Kebutuhan tim analis ini sangat dirasakan juga oleh PT. TAS Semarang, yang selama ini belum memiliki tim khusus untuk kegiatan analisis sistem. Selama ini PT. TAS menggunakan pihak luar dalam kegiatan analisis sistem. Dengan kondisi tersebut maka pihak PT. TAS merasa perlu memberikan pengetahuan dan keterampilan bagi tim analis, hal ini disambut baik oleh tim pengabdian masyarakat untuk melakukan pelatihan dengan materi analisis dan perancangan menggunakan software enterprise architect. Kegiatan dilakukan dengan cara memberikan pelatihan secara langsung kepada peserta pelatihan, yaitu dengan ceramah penyampaian materi, praktek menggunakan software, latihan-latihan serta dilakukan evaluasi hasil rancangan peserta pelatihan dengan cara berdiskusi dan tanya jawab secara langsung pada saat kegiatan dilaksanakan. Dengan adanya pelatihan yang diberikan diharapkan dokumentasi terkait kegiatan analisis dan perancangan sistem di PT. TAS dapat terdokumentasi dengan baik serta tidak lagi bergantung dengan pihak luar.
\end{abstract}

Kata Kunci: analisis dan perancangan, enterprise architect, pelatihan

\section{Abstract}

This community service has a purpose to provide knowledge and skills in information system analysis and design activities for the system analysis team of PT. TAS semarang. Analysis and design is a stage in system development, the goal is to get a clear picture and detail of 
what will be done. Activities carried out include analysis of functional and non-functional requirements of the system. Functional requirements aim to obtain information that contains what processes will be carried out later. The purpose of analyzing non-functional requirements is to obtain information related to needs including the behavior properties possessed by the system. The analysis step is the key to the suitability of the system to be developed with user needs. Therefore, it is very important for a system development team to be able to carry out the analysis correctly and use the correct rules. The requirement for this team of analysts is also felt by PT. TAS Semarang, which so far does not have a special team for system analysis activities. For system analysis and design activities, PT. TAS uses external parties in their daily activities. With these conditions, the PT. TAS feels the need to provide knowledge and skills for the team of analysts, this was welcomed by the community service team to conduct training and assistance with analysis and design materials using enterprise architect software. The implementation of activities is carried out by means of Implementation of activities is carried out by providing direct training to participants namely by delivering material with live lectures, practice using EA software, exercises, as well as an evaluation of the results of the participants' training as well as an evaluation of the results of the participants' training, discussions and direct questions and answers on community service activities. With the training provided, it is hoped that documentation related to system analysis and design activities at PT. TAS can be well documented and no longer depend on outside parties.

Keyword: anlysis and design, enterprise architect, training

\section{Pendahuluan}

Analisa dan Perancangan Sistem merupakan tahapan dalam pengembangan sistem yang menentukan hasil dari sistem yang dibangun atau yang akan dikembangkan agar sesuai dengan kebutuhan yang diinginkan oleh pengguna. (George \& Valacich, 2017)

Analisis sistem merupakan proses yang menjelaskan data maupun informasi secara utuh untuk keperluan evaluasi terkait hambatan maupun permasalahan yang terkandung didalamnya(Tilley \& Rosenblatt, 2020). Secara umum fungsi dari analisis sistem untuk memecahan permasalahan serta mencari solusi dari permasalahan yang ada. Analisis sistem diartikan juga sebagai media pembelajaran dari sistem yang ada dengan tujuan untuk mengembangkan atau membangun sistem baru. Orang yang melakukan kegiatan analisis sistem sering disebut sebagai sistem analis. Untuk meneliti sistem yang sedang berjalan dibutuhkan suatu proses analisis sistem agar sistem dapat berjalan sesuai dengan tujuan yang dikehendaki. Menurut Taufiq, 2013 dalam (Muhidin et al., 2017) menjelaskan bahwa analisis sistem merupakan aktifitas dalam mempelajari sistem baik sistem yang sudah terkomputerisasi (otomatis) maupun sistem degan aktifitas yang dijalankan secara manual secara menyeluruh melalui kegiatan analisis sistem, menganalisa masalah, perancangan logik serta dapat memberikan keputusan dan hasil dari kegiatan analisis tersebut.

Setelah tahap analisis sistem selesai dilakukan, maka analis sistem telah mendapatkan gambaran dengan jelas apa yang harus dikerjakan. Selanjutnya setelah 
tahap analisis sistem adalah tahap bagaimana membentuk sistem, tahap ini disebut dengan tahap perancangan sistem. Menurut Varzello / John Reuter III dalam (Hidayatulloh et al., 2020) Tahap perancangan sistem merupakan tahapan awal yang dilakukan dalam membangun sebuah sistem. Yang dimaksud dengan kegiatan perancangan sistem adalah tahapan dari siklus pengembangan sistem yang mendefinisikan kebutuhan fungsional sistem serta bagaimana sistem dibentuk dan digambarkan. Salah satu hal yang sangat penting adalah kebutuhan sistem yang jelas dan terstruktur dengan baik dalam kegiatan analisis sistem, karena akan digunakan sebagai dasar untuk kegiatan proses pengembangan sistem selanjutnya. Pengembang sistem akan bisa melakukak pekerjaan teknis lainnya jika kebutuhan sistem sudah ditetapkan. Kebutuhan tersebut meliputi perancangan sistem, pengembang, pengujian, implementasi serta kegiatan operasional sistem dapat berjalan dengan lancar (Kosasi \& Kuway, 2012). Analis sistem bertanggung jawab atas penyediaan kebutuhan sistem yang akan dikembangkan

Cara menggambar sistem yang akan dibentuk dapat berupa gambar atau sketsa yang meliputi rancangan diagram entitas serta rancangan antarmuka pengguna (Satzinger Jackson Burd Staff., 2009). Tujuan dari perancangan sistem secara umum adalah memberikan gambaran kepada pengguna sistem secara umum mengenai sistem yang baru. Selain itu juga bertujuan untuk memberikan gambaran mengenai rancangan (desain) program yang dikerjakan secara jelas serta untuk mengimplementasikan hasil dari tahap analisa dalam sebuah gambar yang dapat dipahami oleh programer. Jogiyanto, 2017 dalam (Saputra, 2017)

PT. TAS (Teknologi Aplikasi Sejahtera) Semarang adalah salah satu perusahaan yang bergerak dibidang Teknologi Informasi dan Industri Kreatif dimana kegiatan yang dilakukan setiap harinya diantaranya adalah mengembangkan sistem atau membangun sistem sesuai dengan kebutuhan user. Dengan demikian maka salah satu kegiatan atau tahapan yang harus dilakukan adalah tahapan dalam analisa dan juga merancang sistem yang akan dikembangkan.

Penelitian yang dilakukan The Standish Group (2001) menghasilkan kesimpulan bahwa kegagalan dalam kegiatan pengembangan perangkat lunak disebabkan karena kegagalam dalam mengantisipasi spesifikasi kebutuhan sistem yang akan dikembangkan. Sedangkan hasil penelitian yang dilakukan terhadap 300 perusahaan besar oleh KPMG dihasilkan kurang lebih 65\% pengembang perangkat lunak mengalami kegagalan dikarenakan anggaran yang dikeluarkan tidak sesuai dengan yang ditargetkan. Waktu pengerjaan pengerjaan proyek melebihi dari waktu yang ditargetkan (Kosasi \& Kuway, 2012).

Analisis persyaratan perangkat lunak dapat dibagi menjadi lima area kerja, yaitu pengenalan masalah, evaluasi dan sintesis, pemodelan, spesifikasi dan kajian spesifikasi (Pressman \& Maxim, 2019). (Suryn, 2014) Analisis persyaratan dari suatu sistem selalu dimulai dengan komunikasi diantara 2 (dua) unit atau lebih dengan cara wawancara

Sebagian besar karyawan PT. TAS merupakan tenaga ahli yang mahir di pemrograman. Sedangkan untu kebutuhan analisis dan perancangan sistem yang 
dikembangkan menggunakan pihak luar. Kebutuhan akan tenaga ahli dalam kegiatan analisis daan perancangan sistem sangat dirasakan oleh perusahaan, hal ini dikarenakan perusahaan harus mengeluarkan anggaran yang tidak sedikit juga untuk kebutuhan analisis dan perancangan sistem ini. Selain biaya yang menjadikan permasalahan, ketergantungan dengan pihak luar seringkali menjadi kendala saat harus menyelesaikan sistem segera tetapi perusahaan harus menunggu hasil dari pihak luar.

Adanya kondisi yang ada inilah maka kegiatan pelatihan analisa dan perancangan sistem bagi tim analis PT. TAS Semarang dilaksanakan. Tujuan dari kegiatan pelatihan ini diharapkan kedepannya perusahaan tidak lagi tergantung dengan pihak luar dalam kegiatan analisis dan perancangan dalam penyelesaian projekprojek yang ada. Selain itu perusahaan memiliki dokumentasi terkait pengembangan sistem yang dilakukan secara terstuktur dan mengikuti kaidah-kaidah yang ada dalam merancang sistem informasi sehingga dapat memenuhi kebutuhan pengguna(Adiguna et al., 2018). Perangkat dokumentasi yang lengkap merupakan salah satu syarat untuk kebutuhan sistem adalah harus dimiliki. Dokumen yang harus tersedia meliputi entitas pengguna sistem, tujuannya untuk menspesifikasi persyaratan dan untuk mengecek apakah sudah memenuhi kebutuhan yang diharapkan oleh pengguna sistem nantinya. Selanjutnya entitas manajer, hal ini dimaksudkan untuk membuat perencanaan terkait penawaran atas sistem serta perencanaan untuk proses pengembangan sistem yang akan dikerjakan. Entitas yang tidak boleh terlewatkan adalah entitas pengembang sistem (perekayasa sistem) bertujuan untuk memahami proses sistem yang akan dikembangkan. Selanjutnya adalah entitas perekayasa pengujian sistem, bertujuan untuk proses pengembangan pengujian validasi sistem. Dan yang terakhir adalah entitas perekayasa pemeliharaan sistem, tujuan adalah untuk membantu pemahaman sistem dan keterkaitan diantara unit-unit yang tergabung didalam sistem yang akan dikembangkan (Sommerville, 2011).

\section{Metode}

Metode pelaksanaan kegiatan pengabdian masyarakat ini diantaranya adalah dimulai dari presentasi, praktek, projek dan evaluasi

a. Ceramah dan Tanya Jawab

Metode ceramah merupakan metode penjelasan materi yang dilakukan dengan cara lisan oleh pengajar (instruktur) kepada peserta di depan forum (Savira et al., 2018). Pada kegiatan pengabdian ini ceramah dilakukan dengan cara presentasi penyampaian materi secara langsung dimana instruktur menyampaikan materi terkait analisis dan perancangan sistem yang dilakukan diruang pertemuan di tempat mitra. Peserta diberikan kesempatan untuk bertanya jika ada materi yang kurang dipahami.

b. Praktek

Metode praktek adalah metode dengan menggunakan bahasa secara intensif secara langsung dalam berkomunikasi. Metode praktek dikenal dengan cara 
diberikan latihan-latihan terkait materi yang dipelajari (Cahyaningrum, 2019). Instruktur memberikan contoh-contoh dan praktek langsung terkait materi yang disampaikan dengan menggunakan software yang telah disiapkan sebelumnya agar pelaksaan pengabdian dapat berjalan lancar. Peserta mengikuti penjelasan serta mempraktekkan materi yang diberikan dengan menggunakan perangkat komputer masing-masing.

c. Projek

Peserta diberikan studi kasus, untuk diselesaikan permasalahan yang ada serta dibuat penyelesain dengan cara berdiskusi dengan peserta lainnya serta mempresentasikan hasil pekerjaannya di forum kegiatan.

d. Evaluasi

Evaluasi dilakukan dengan cara diskusi langsung pada saat peserta pelatihan mempresentasikan hasil projek yang dikerjakan. Evaluasi dilakukan oleh instruktur yang merupakan tim pengabdian, dan juga evaluasi dari peserta lain untuk memberikan masukkan terkait projek yang dikerjakan.(Hasim et al., 2021)

\section{Hasil dan Pembahasan}

Pelaksanaan Kegiatan Pengabdian Kepada Masyarakat ini dilakukan di PT. TAS Semarang yang beralamatkan di Jl. Plamongan Indah Blok E No. 17 Semarang. Kegiatan pelatihan yang dilakukan oleh tim pengabdian dilaksanakan di ruang pertemuan PT. TAS Semarang. Jarak lokasi pengabdian kepada masyarakat dengan kampus Universitas Stikubank Semarang sekitar $\pm 12 \mathrm{Km}$. Lokasi pengabdian sangat mudah dijangkau oleh tim pengabdian dan juga peserta pengabdian. Tim pengabdian adalah dosen di Fakultas Teknologi Informasi dan juga dibantu oleh mahasiswa.

Untuk kelancaran proses pelaksanaan kegiatan Pengabdian Kepada Masyarakat yaitu Kegiatan Pelatihan Perancangan Sistem Menggunakan Software Enterprise Architect ini dilakukan komunikasi langsung antara ketua tim pengabdian dengan pihak PT. TAS. Selanjutnya untuk teknis pelaksanaan dan koordinasi kegiatan yang akan dilakukan, Tim Pengabdian langsung berkomunikasi dngan salah satu peserta yang dipilih untuk mengkoornir peserta pengabdian yang lainnya. Komunikasi Tim Pengabdian dengan Koordinator peserta pelatihan dilakukan menggunakan fasilitas handphone dan dan juga whatsapp yang merupakan sarana komunikasi saat ini memudahkan orang untuk komunikasi.

Pelaksanaan kegiatan Pengabdian Kepada Masyarakat ini melibatkan tim pengabdian yaitu terdiri dari dosen dan dibantu mahasiswa. Jumlah tim dosen yang terlibat dalam Pengabdian Kepada Masyarakat ini adalah sejumlah 3 (tiga) orang dosen dengan pendidikan S2 Ilmu Komputer dan 1 (satu) dosen bergelar doktor Ilmu Komputer yang merupakan dosen di Fakultas Teknologi Informasi Universitas Stikubank Semarang. Tim Pengabdian Kepada Masyarakat ini terdiri dari 2 (dua) dosen dari Program Studi Sistem Informasi dan 2 (dua) dosen dari Program Studi Teknik Informatika. Sedangkan mahasiswa yang terlibat dalam pengabdian ini 
sejumlah 2 (dua) orang mahasiswa Program Studi S1 Sistem Informasi Fakultas Teknologi Informasi Unisbank Semarang.

Materi yang disampaikan pada kegiatan pengabdian kepada masyarakat adalah pelatihan analisa dan perancangan sistem berbasis objek menggunakan software Enterprise Architect. Tools analisis dan perancangan menggunakan UML (Unified Modeling Language) yang merupakan metode yang populer saat ini untuk memvisualisasikan konstruksi dari desain sistem yang akan dikembangkan. UML sendiri menurut (Kenneth E \& Julie E, 2011) "UML approach is well worth invesgating and understanding, due to its wide acceptance and usage". Untuk mengkonstruksi desain sistem dapat divisualisasikan menggunakan model UML dengan berbagai diagram yang ada meliputi use case diagram, aktivity diagram, dan juga class diagram. Seringkali juga perancangan sistem dilengkapi dengan perancangan input output agar programmer lebih mudah memahami proses dalam sistem (Kenneth E \& Julie E, 2011).

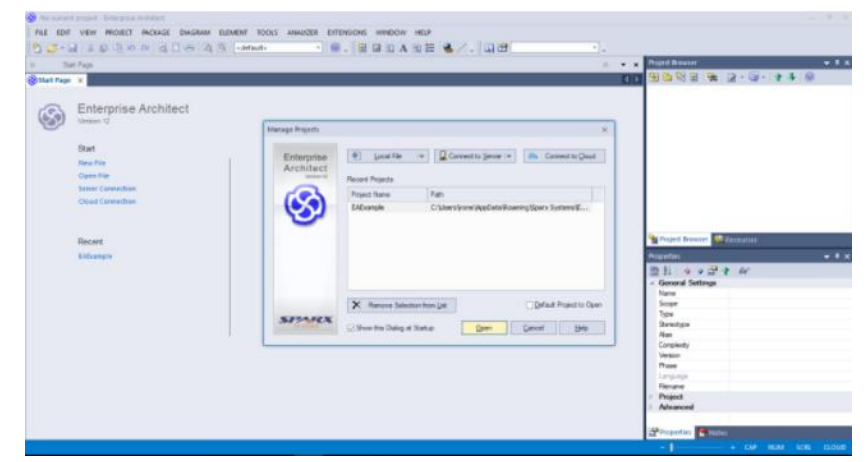

Gambar 1. Software Enterprise Architect

Pada kegiatan pengabdian kepada masyarakat akan disampaikan materi diagram use case, diagram kelas dan diagram aktifitas yang akan didesain menggunakan software Enterparise Architect, dengan menginstalasi software enterprise architect terlebih dahulu ke laptop masing-masing untuk kelancaran proses pelatihan (Gambar 1). Peserta diberikan materi terkait konsep, aturan-aturan baku dalam penggunaan diagram UML, selanjutnya tim pengabdian sebagai instruktur akan memberikan contoh khasus untuk diselesaikan menggunakan diagram UML, serta akan mempraktekkan menggunakan software enterprise architect dalam memvisualisasikan kontruksi desain sistem yang telah dibuat (Gambar 2)

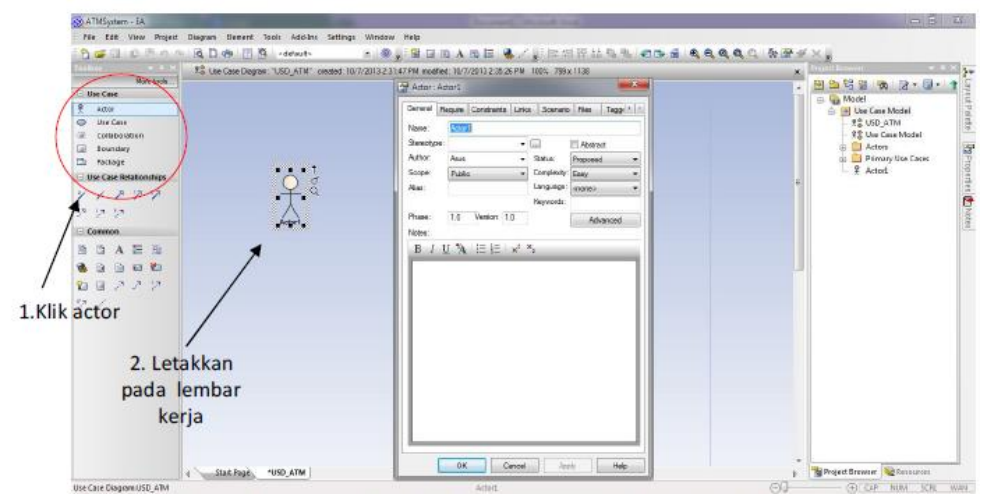

Gambar 2. Contoh Mendesain Use Case Diagram 
Bentuk pelaksanaan Kegiatan Pengabdian Kepada Masyarakat yang dilakukan untuk Tim Analis Sistem PT. TAS ini dilakukan dengan cara pelatihan kepada peserta. Pelatihan dilakukan dengan memberikan materi konsep dan teori secara langsung kepada peserta (Gambar 3). Selanjutnya peserta juga diberikan pelatihan menggunakan software perancangan yang dapat langsung dipraktekkan. Peserta pelatihan dengan menggunakan komputer/laptop yang mereka miliki untuk sarana bekerja dapat langsung mempraktekkan materi yang diberikan saat pelatihan (Gambar 4) Penyampaian materi pelatihan dilakukan dengan cara memberikan pengetahuan dan informasi secara langsung contoh-contoh kasus sistem dan juga kasus-kasus yang selama ini ditangani oleh peserta pelatihan di pekerjaan yang selama ini ditekuni dan harus dikerjakan. Dengan demikian maka peltihan langsnug menyelesaikan kasus-kasus yang selama ini menjadi permasalahan dalam pekerjaan peserta pelathan. Pelatihan dilakukan dengan menggunakan perangkat Komputer berupa laptop dari yang dimiliki oleh peserta dan juga merupakan fasilitas kantor yang diberikan oleh PT. TAS Semarang untuk fasilitas kerja tim analisis sistem yang dalam hal ini sebagai peserta pelatihan pengabdian masyarakat.

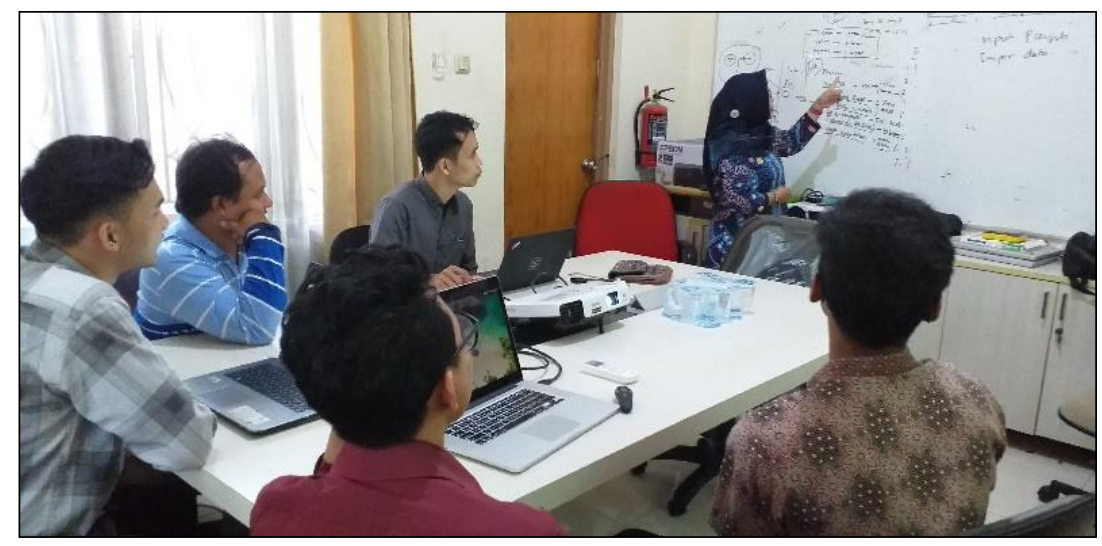

Gambar 3. Tim Pengabdian Menyampaikan Materi

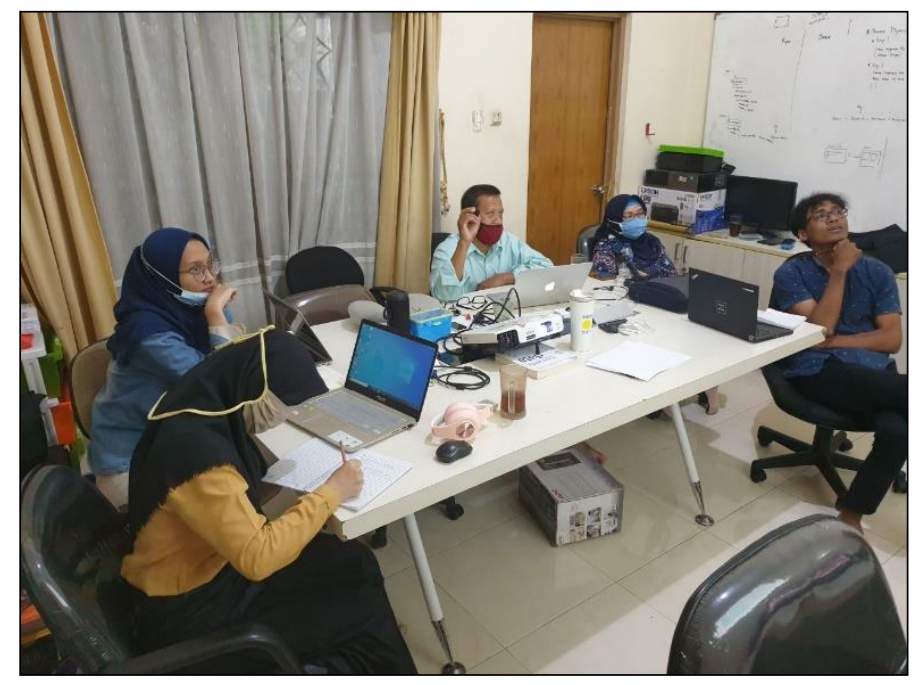

Gambar 4. Peserta Mengikuti Penjelasan dan Mempraktekkan 
Tim pengabdian menjelaskan materi pelatihan secara konsep dan teori perancangan sistem berbasis objek, dan dilanjutkan dengan tahapan dalam perancangan menggunakan diagram UML. Tim memberikan contoh dalam proses perancangan sistem menggunakan UML yaitu meliputi perancangan Diagram Use Case, Activity Diagram, Class Diagram. Dilanjutkan pula pelatihan dalam menggunakan software enterprise architect untuk menggambarkan masing-masing diagram (Gambar 5). Pada saat penjelasan konsep peserta mendengarkan dengan seksama, selanjutnya peserta akan mempraktekkan cara memanfaatkan tools untuk menggambar UML dengan baik dan benar. Pelaksanaan kegiatan ini dapat dikatakan berjalan dengan lancar, hal ini juga dikarenakan peserta mempraktekkan materi yang disampaikan tim pengabdian sebagai instruktur dengan menggunakan fasilitas laptop masing-masing sehingga lebih memudahkan dan efisiensi waktu pelatihan.

Peserta pelatihan menerapkan materi yang disampaikan tim pengabdian dengan membuat perancangan dari kasus dengan dibuat diagram use case, class dan activity diagram, serta mempraktekan software enterprise architect untuk membuat diagramdiagram tersebut. Peserta sangat antusias dalam mengikuti pelatihan yang diberikan, karena materi yang diberikan merupakan materi yang dibutuhkan untuk penyelesaian pekerjaan mereka sehari-hari di PT. TAS Semarang nantinya. Dengan pengetahuan dan keterampilan yang diberikan peserta semakin termotivasi dalam bekerja dan meyelesaikan tugas sehingga dokumentasi yang dihasilkan dapat lebih terstruktur dengan baik dan memenuhi kaidah-kaidah yang benar.

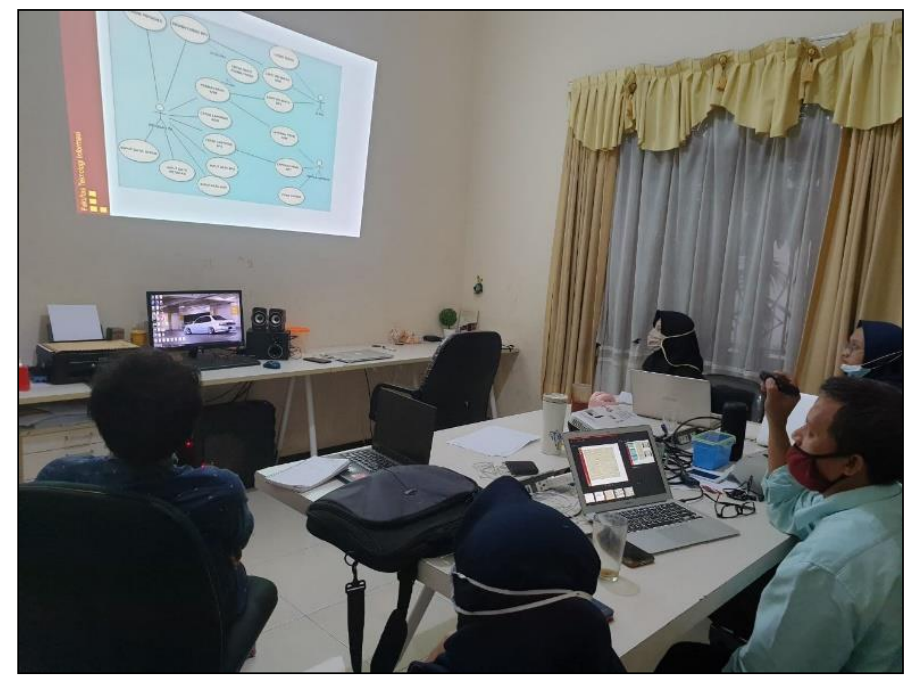

Gambar 5. Tim Pengabdian Mempraktekan Software Enterprise Architect

Pada kegiatan pelatihan Pelatihan Analisa dan Perancangan Sistem Menggunakan Software Enterprise Architect ini dilakukan juga evaluasi kegiatan. Hal ini dilakukan agar dapat mengukur seberapa jauh tingkat keberhasilan peserta dalam memahami materi yang disampaikan oleh instruktur pelatihan. Bentuk evaluasi kegiatan dilakukan adalah dengan melihat secara langsung dari aktivitas peserta dalam mempraktekkan penjelasan yang diberikan oleh instruktur (tim pengabdian). 
Pelaksanaan pelatihan dengan cara instruktur menjelaskan dan mempraktekkan materi, kemudian peserta pelatihan mendengarkan dan mempraktekkan langsung materi yang disampaikan instruktur dengan didampingi oleh tim pengabdian yang lain serta mahasiswa sebagai asisten pelatihan. Instruktur pelatihan selain menjelaskan dan mempraktekkan juga memberikan contoh-contoh yang dengan mudah dipahami oleh peserta dan dapat diikuti serta dipraktekkan oleh peserta (Gambar 6). Tim pengabdian sebagai instruktur pelatihan memberikan soal studi kasus yang harus dikerjakan oleh peserta pelatihan. Selain itu juga kasus-kasus projek yang selama ini ditangani oleh tim analis juga menjadi bahan diskusi penyelesaian masalah dalam kegiatan pengabdian. Hal ini juga untuk mengurangi kejenuhan bagi peserta pelatihan. Jika semua peserta telah selesai mempraktekkan dan tidak ada pertanyaan yang disampaikan maka instruktur akan melanjutkan materi berikutnya. Begitu seterusnya hingga materi selesai dan dilanjutkan dengan bahasan materi yang berbeda oleh instruktur yang berbeda sampai semua materi selesai disampaikan ke peserta pelatihan.

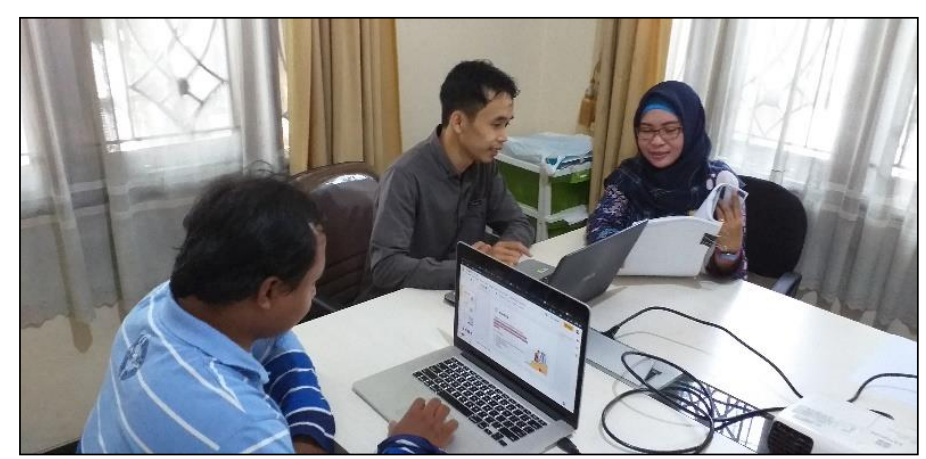

Gambar 6. Instruktur Memberikan Pengarahan dan Contoh

\section{Simpulan dan Rekomendasi}

Berdasarkan pelaksanaan pengabdian kepada masyarakat yang telah dilaksanakan, maka dapat dibuat kesimpulan sebagai berikut: (1) Pelatihan tentang Analisis dan Perancangan Sistem memberikan bekal dan pengetahuan bagi Tim Analis Sistem PT. TAS yang selama ini sangat minim memiliki pengetahuan terkait analisis dan perancangan sistem. (2) Pelatihan tentang Analisis dan Perancangan Sistem yang diberikan oleh tim pengabdian dapat dipakai dasar untuk dapat menyusun dokumentasi projek agar dapat terdokumentasi dengan baik dan terstruktur. (3) Pelatihan yang dapat mengurangi ketergantungan perusahaan dengan pihak luar dalam kegiatan analisis dan perancangan sistem.

\section{Daftar Pustaka}

Adiguna, A. R., Saputra Chandra, M., \& Pradana, F. (2018). Analisis dan Perancangan Sistem Informasi Manajemen Gudang pada PT Mitra Pinasthika Mulia Surabaya. Jurnal Pengembangan Teknologi Informasi Dan Ilmu Komputer, 2(2), 612-621. 
Cahyaningrum, N. H. (2019). Keefektifan Metode Praktik Langsung Dan Metode Audiolingual Dalam Pembelajaran BIPA Aspek Berbicara Bagi Pemelajar BIPA 4 UNNES. Jurnal Pendidikan Bahasa Dan Sastra Indonesia, 1(1), 44-59.

George, J. F., \& Valacich, J. S. (2017). Modern Systems Analysis and Design - 8th Edition.

Hasim, H., Hasniah, H., \& Arsyam, M. (2021). Teknik Dan Bentuk Evaluasi Hasil Belajar. Ddi. http://dx.doi.org/10.31219/osf.io/m4yk5

Hidayatulloh, K., MZ, M. K., \& Sutanti, A. (2020). Perancangan Aplikasi Pengolahan Data Dana Sehat Pada Rumah Sakit Umum Muhammadiyah Metro. Jurnal Mahasiswa Ilmu Komputer, 1(1), 18-22. https:// doi.org/10.24127/.v1i1.122

Kenneth E, K., \& Julie E, K. (2011). SYSTEMS ANALYSIS AND DESIGN (8th ed.). Pearson Education, Inc.

Kosasi, S., \& Kuway, S. M. (2012). Studi Analysis Persyaratan Kebutuhan Sistem dalam Menghasilkan Perangkat. Sisfotenika, 2(1), 1-10.

Muhidin, R., Kharie, N. F., \& Muin, K. (2017). IJIS Indonesian Journal on Information System ISSN 2548-6438. IJIS-Indonesia Journal on Information System, 2(September), 56-68. https://doi.org/10.36549/ijis.v2i2.31

Pressman, R. S., \& Maxim, B. R. (2019). Software Engineering : A Partitioner's Approach.

Saputra, D. (2017). Modul Pembelajaran Analisa \& Perancangan Sistem Informasi. Journal of Chemical Information and Modeling, 53(9), 1689-1699.

Satzinger Jackson Burd Staff. (2009). Systems Analysis and Design in a Changing World 5th (Fifth) - Chapter 2.

Savira, A. N., Fatmawati, R., Rozin Z, M., \& Eko S, M. (2018). Peningkatan Minat Belajar Siswa Dengan Menggunakan Metode Ceramah Interaktif. Factor M, 1(1), 43-56. https://doi.org/10.30762/f_m.v1i1.963

Sommerville, I. (2011). Software Engineering (9th ed.; Boston, Ed.). Massachusetts: Pearson Education.

Suryn, W. (2014). Software Quality Engineering: A Practitioner's Approach. In Software Quality Engineering: A Practitioner's Approach (Vol. 9781118592). https://doi.org/10.1002/9781118830208

Tilley, S., \& Rosenblatt, H. (2020). Systems Analysis and Design, Eleventh Edition. In Course Technology. 